\title{
Core Skills Assessment to Improve Mathematical Competency
}

Michael Carr ${ }^{1}$, Brian Bowe ${ }^{1}$ and Eabhnat Ní Fhloinn ${ }^{2}$

${ }^{I}$ Faculty of Engineering, Dublin Institute of Technology, Dublin, Ireland

${ }^{2}$ School of Mathematical Sciences, Dublin City University, Dublin, Ireland

Corresponding author: michael.carr@dit.ie

This is an Accepted Manuscript of an article published by Taylor \& Francis in European Journal of Engineering Education in 2013, available

online: http://www.tandfonline.com/10.1080/03043797.2012.755500 


\section{Core Skills Assessment to Improve Mathematical Competency}

Many engineering undergraduates begin third-level education with significant deficiencies in their core mathematical skills. Every year, in the Dublin Institute of Technology (DIT), a diagnostic test is given to incoming first-year students, consistently revealing problems in basic mathematics. It is difficult to motivate students to address these problems; instead, they struggle through their degree, carrying a serious handicap of poor core mathematical skills, as confirmed by exploratory testing of final year students.

In order to improve these skills, a pilot project was set up in which a "module" in core mathematics was developed. The course material was basic, but $90 \%$ or higher was required to pass. Students were allowed to repeat this module throughout the year by completing an automated examination on WebCT populated by a question-bank. Subsequent to the success of this pilot with thirdyear mechanical engineering students, the project was extended to five different engineering programmes, across three different year-groups. Full results and analysis of this project are presented, including responses to interviews carried out with a selection of the students involved.

Keywords: diagnostic testing; core mathematical skills; basic mathematics improvement

\section{Introduction}

Increasingly, students who enter third level engineering programmes struggle with core mathematical competencies (e.g. converting units, indices, dealing with fractions and basic algebra). This has been demonstrated in the results of diagnostic tests carried out in many third level institutions, both in Ireland (Gill 2007, Cleary 2007, Faulkner 2010, Carr et al 2010) and in the United Kingdom (Todd 2001, Edwards 1995, Lawson 1997, Lawson 2003). This marked increase in poor mathematical competency has been due to a mixture of effects. 
Firstly, a particular grade at second level may no longer correspond to the same level of competency as previously. This has been repeatedly observed in the United Kingdom, with Todd (2001) finding that "A student with an A at A-level mathematics today will on average, obtain a score on our test which would have placed them near the bottom of the cohort fifteen years ago" while Lawson (2003) says "students entering in 2001 with A level mathematics grade B exhibit slightly lower levels of competency in these basic skills than those entering 10 years earlier with a grade $N " 1$. In Ireland, however, this has not been the case. While there is evidence of grade inflation in the Irish Leaving Certificate in most subjects (O’Grady, 2009), Faulkner et al (2010) have shown that the competencies of "students with the same Leaving Certificate mathematics grade on entry into university have not changed significantly over time" and that the decline in mathematical competency in Ireland is due to the lower Leaving Certificate mathematics grades of the students on entry to third level.

These problems with core competencies lead to comprehension difficulties in a range of engineering modules, both in mathematics and related subjects. In recent years in Ireland, this has been exacerbated by the fact that students are being recruited from an increasingly diverse student body. The academic years of $2008-2012$, in particular, have seen the return of a large number of students to full-time education after many years in employment, due to adverse economic conditions.

In this paper, we discuss the mathematics diagnostic test carried out in the Dublin Institute of Technology (DIT) and the deficiencies in students' core mathematics revealed by this test. The details of a project in assessment carried out to address these deficiencies are outlined below and the results of several focus groups are presented.

\footnotetext{
${ }^{1}$ A grade $\mathbf{N}$ means insufficient
} 
The maths diagnostic test was also given to a selection of fourth year students and the results of this test are shown. Finally we outline future work we intend to carry out on this project.

\section{Core Skills Initiative}

\subsection{Irish Leaving Certificate}

Entry into third level in Ireland is usually exclusively based on the number of points obtained in the Leaving Certificate, the final examination in secondary school.

Normally students sit seven subjects and six of these are included for the purposes of calculating points. Mathematics exams can be taken at Higher, Ordinary or Foundation level. Students who take mathematics at Foundation level are not eligible for direct entry to third level. Mathematics is a compulsory subject and $96 \%$ of Leaving Certificate students sit an exam in mathematics (Breen et al., 2008). A maximum of 100 points can be attained in any one subject; a perfect score is 600 is achieved by about $0.2 \%$ of students and the median score is usually around 320-330 points (www.cao.ie).

\subsection{Engineering Degrees in Ireland}

In Ireland, 55\% or more in Higher level mathematics is required for entry to a fouryears Honours degree in engineering, while $40 \%$ or more in Ordinary level mathematics is required for entry to a three-year Ordinary degree in Engineering. Upon successful completion of an Ordinary degree, students may enter into third year of the Honours degree (see Figure 1). 


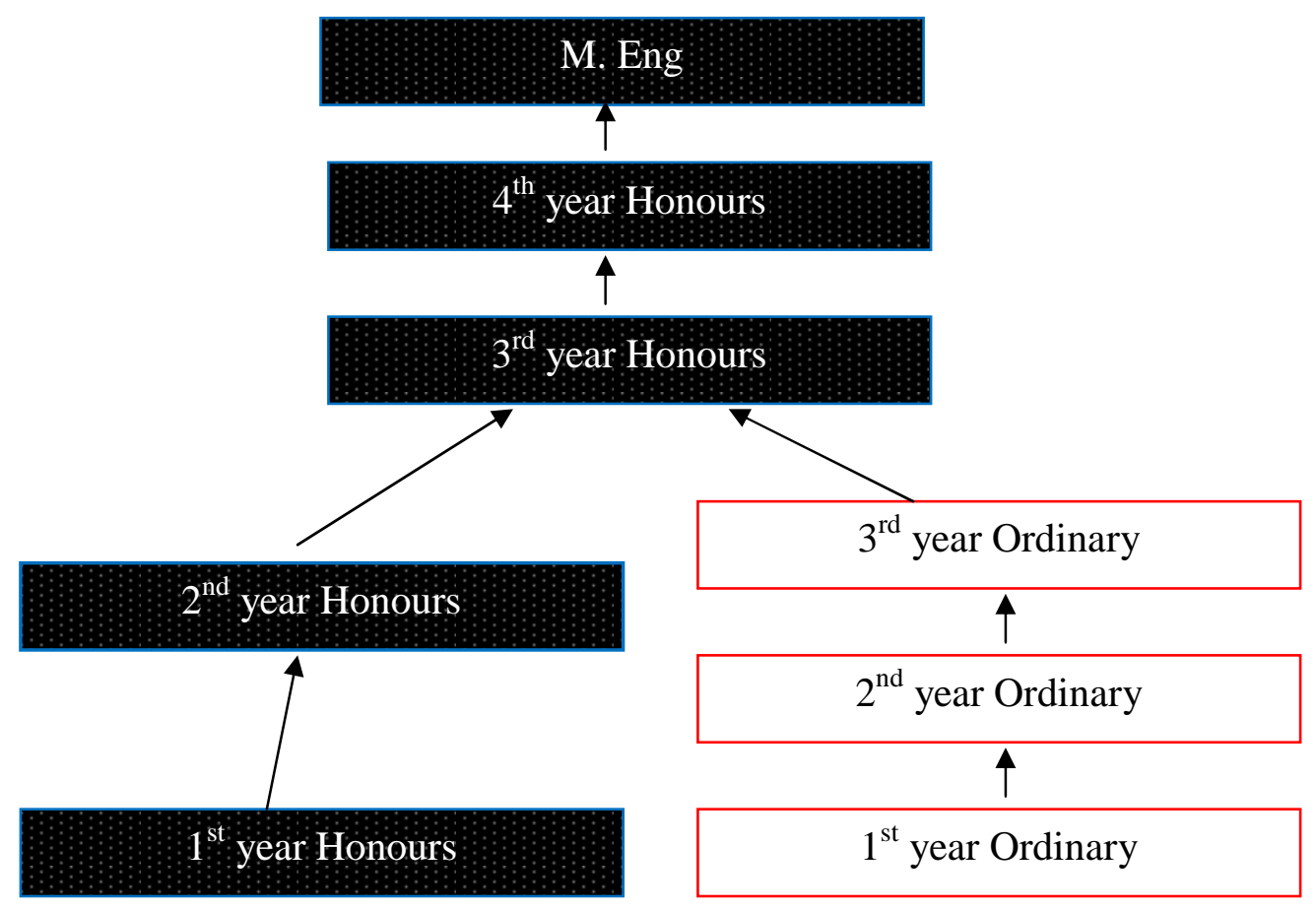

Figure 1. Routes to an Honours degree in Engineering.

\subsection{Mathematics Diagnostic Test}

Research conducted by the Dublin Institute of Technology (DIT) Retention Office showed that a student's mathematics grade in the Leaving Certificate is a key determinant in that student's progression through engineering programmes (Russell, 2005). As a result, a mathematics diagnostic test has been given to first year students for several years now and a Maths Learning Centre (MLC) has been set up.

Mathematics diagnostic tests have been shown to be one of the best predictors of future performance in an engineering course (Lee \& Robinson, 2008). The DIT Mathematics Diagnostic Test showed marked deficiencies in core mathematical skills (Ni Fhloinn, 2006), in particular converting units, indices, dealing with fractions and basic algebra. The test consists of twenty multiple-choice questions on basic topics such as algebra, fractions, indices, trigonometry, the equation of a line, logs, quadratic 
equations, simultaneous equations and basic differentiation (Appendix 1). As recommended by Lee \& Robinson (2005), all questions are "paired", thus decreasing the chance of a student guessing the correct answer to any topic. In 2006, the mean mark obtained by first year engineering students was 55\% across all programmes. More worryingly, this mean dropped as low as $29 \%$ in some programmes. Similar marks are recorded for other years. A large spread was seen within most programmes, with many students scoring significantly lower than the mean mark.

It is important that diagnostic testing does not simply exist in isolation, but is seen as a means to an end:

\footnotetext{
"Diagnostic testing should be seen as part of a two-stage process. Prompt and effective follow up is essential to deal with both individual weaknesses and those of the whole cohort. Without some sort of structured support in place there is a risk that diagnostic testing may be of little benefit to weaker students." (Robinson and
} Croft 2003)

The Maths Learning Centre in DIT was set up to act as a support to students who need additional help. However, students tend to seek help with new material being covered in lectures rather than revising core concepts; a situation that is far from unique to DIT:

\footnotetext{
"In situations where students are simply told their test result and advised to revise certain topics on their own, there is little evidence that this happens." (Lawson et al, 2003, p. 8)
}

As a result, a specific intervention was needed to tackle the problem of poor core mathematical skills in a direct and structured manner.

\subsection{Core Skills Assessment (CSA)}

The key to changing patterns of student learning is assessment, as noted by a range of authors. As far back as 1992, Ramsden (1992) noted that "From our students' point of 
view, assessment always defines the actual curriculum". Brown et al (1997) go further, observing that

\footnotetext{
"Assessment defines what students regard as important, how they spend their time and how they come to see themselves as students and then as graduates. If you want to change student learning then change the methods of assessment."
}

Much of the material covered in the Mathematics Diagnostic Test is on the syllabus of the first year Ordinary Degree mathematics modules. But because of the nature of the assessments involved, it is possible to obtain marks of over $50 \%$ without mastering the basics. Sometimes, such "basic material" does not feature on the exam paper. Anecdotally, based on many years of correcting examination scripts, we have found that many students progress through more complicated "recipe-type" questions only to make basic mistakes at the end. Behaviour like this is rarely severely punished and students limp through from year to year with poor basic competencies. This is especially important in a subject like Engineering, where it is the final result that is important. It is of no use if an Engineer can half do a problem if in the end the result is incorrect.

It was decided to devise the Core Skills Assessment (CSA) in mathematics, similar to those already in existence in the Institute of Technology Tallaght, Dublin (Marjoram et al 2008) and the London South Bank University (Warwick 2010). The CSA consisted of a multiple-choice quiz on WebCT, based on a randomised question bank. While the material was basic, the pass mark was set at $90 \%$ for third year students and $70 \%$ for first years. The questions were based on those already in use in the DIT Mathematics Diagnostic Test. Students were allowed to re-sit the CSA as frequently as required until they passed. As this test is worth $10 \%$ of the credit for the module, students who fail to pass the CSA receive 0/10 for this part of the module. This serves 
as a strong motivating factor for most of the students. Ideally, a pass in the CSA would be compulsory for progression to the next year of the course, but this is not yet the case.

\section{Methodology}

Five different groups spanning a range of degree programmes and years were chosen for this study. Details of these groups, as well as the minimum Leaving Certificate points required for entry, are given in Table 1. [Table 1 near here]. Preliminary Engineering is a DIT foundation programme in Engineering specifically aimed at students who do not have higher level Maths.

\subsection{Project Overview}

The CSA was worth $10 \%$ of the mathematics module grade. During the first two weeks of the academic year, all students sat the computer-based Mathematics Diagnostic Test, for which they were allowed 90 minutes and received immediate feedback. This feedback consisted of their total score, which questions they have gotten wrong and the correct answers to these questions. There were two different marking regimes depending on the class year involved. Third-year students who received $90 \%$ or higher were deemed to have passed the CSA, and received either nine or ten marks towards their mathematics module grade. Those who failed to obtain $90 \%$ received no marks and had to take the CSA at a later date. For first and second year students, a sliding scale was used whereby those who obtained $70 \%$ got 4 marks; $80 \%$ was worth 6 marks; $90 \% 8$ marks and $100 \% 10$ marks

Students continued to sit the CSA on a monthly basis until they achieved the required pass mark, and had from September until early May to do so (a total of 22 teaching weeks). 
After their first attempt, students were given access to a WebCT site with resources tailored for each question and were also encouraged to attend the Maths Learning Centre.

After their second and subsequent attempts, special optional classes on problematic topics were provided. These classes were well attended with 10-20 students on average giving up their lunchtimes for extra maths classes. At the end of the year, selected students took part in focus groups to discuss the project.

\subsection{Evaluation of the Core Skills Assessment (CSA)}

An evaluation strategy was devised in order to enhance and develop the CSA and the way in which it is implemented in, and integrated into, the modules. The evaluation is essentially a comparison between aims and objectives of the development and implementation of the test and the reality of the students' learning and development. There was also a particular need for formative evaluation in order to discover areas where improvements can be made to the test itself and its use within the engineering programmes. The evaluation combines both qualitative and quantitative research methods in order to ascertain the effectiveness of the CSA and to determine where improvements can be made. The methods of data collection are focus groups and test results, as well as the number of attempts made by the students.

\subsection{Focus Groups}

Two focus groups of eight students with different cohorts of students using the CSA were held two weeks before the end of term when most students had already passed the CSA. Hence a comparative analysis of the following groups is possible:

- First year Ordinary degree (6 students) 
- Final year Ordinary degree (6 students, 3 of whom are mature students)

- Preliminary engineering students (4 students)

The focus groups consisted of qualitative questions regarding the students' perceptions and opinions of the maths diagnostic test and the way in which it was implemented within their modules. They were carried out by an experienced education researcher who did not teach any of the students and was not known to the students. Analysis of the focus group data led to the following conclusions:

\subsubsection{Positive Aspects}

(1) The students were able to describe the positive effects the CSA had on the development of their mathematical abilities. They identified not only the ways in which this developed but the role that the CSA had played. They gave concise examples of difficulties they had in mathematics prior to the test and described how these were remedied once identified through the results of the test.

(2) The students were clearly aware of the formative nature and purpose of the CSA even though their final mark contributed to the overall module mark. They were also very cognisant of the need for the CSA to contribute to the module mark and the motivation associated with this.

(3) The students supported the high pass mark and expressed their belief that it is this coupled with having to reach this threshold to get any mark that ensures the effectiveness of the CSA. It should be noted that a significant number of Preliminary Engineering students felt that the pass mark of $70 \%$ was too low. The students appreciated the chance to take the test multiple times and could clearly articulate the formative effect this had on their learning experience and development. 
(4) The importance in engineering of the mathematics examined by the CSA was evident to all students but particularly to students in the latter stages of their engineering programmes.

(5) The quality of the mathematics online notes and the "special" tutorials outside of timetabled hours was commended by the students and described as "professional”, "effective" and "concise".

(6) Confidence in their mathematical ability was perceived as being positively affected by the test (although it should be noted that a number of students said the result after their first attempt was disappointing and had a detrimental effect on their confidence).

(7) The students appreciated the time, effort and commitment of the staff involved in the implementation of the CSA.

\subsubsection{Development Aspects}

(1) The CSA could provide more specific feedback to the students. The students felt the effectiveness could be improved if the result was not just a mark but also suggested how the deficiencies could be rectified. For instance, the CSA could direct students to a particular set of notes, chapter of a book or an online resource. In addition, if the lecturer noticed that a significant number of the students had difficulty with the same section, a tutorial could be run soon after the test to address that specific issue.

(2) It was also suggested that similar diagnostic tests could be developed for specific elements of the mathematics modules. In that way, the full diagnostic test could identify areas of difficulty; the student then addresses this difficulty and can then complete a diagnostic test which only examines that particular area. The mark for this 'smaller' test would not count towards the final module mark 
and the student would still have the opportunity of retaking the full diagnostic test.

(3) The students also expressed the view that a more advanced test could be developed for the latter stages of the engineering programmes, and for the students who excel in the diagnostic test on the first attempt.

(4) All of the students expressed the opinion than the effectiveness of the test could be improved if its purpose, and the most effective way of using it, was clearly communicated to the students at the start of the process and again after the first attempt at completing the test.

(5) It was suggested that greater links between the mathematics being developed within the maths modules (including the diagnostic test) and the other modules within the programmes may also improve the students' mathematical ability.

\subsection{Results of Mathematics Diagnostic Test}

Initially, all students sat the Mathematics Diagnostic Test, and their results are shown in Table 2. [Table 2 near here] On comparison with Table 1, it can be seen that students in those programmes with lower entry-points requirements have a substantially lower mean mark. As a benchmark for the level of mathematics required in an Honours degree in engineering, the Mathematics Diagnostic Test was also given to first year Honours degree students (shown as the first line in Table 2). The majority of these (69 students out of 87 ) scored over $70 \%$ in the Mathematics Diagnostic Test. Improving the core mathematics of this cohort is clearly not a priority when we compare this with the marks of other class groups, as they are better than the marks of the third year students in this study, who have already completed two years of mathematics at third level (albeit at Ordinary degree level rather than Honours). 


\subsection{Overall Improvement}

Students who failed the Mathematics Diagnostic Test entered into the CSA project, and their progress was tracked throughout the year. Overall, there was a systematic improvement in the core mathematical skills of these students as measured by the CSA. To illustrate this point, we will consider in detail one of the weakest cohorts (Preliminary Engineering) from October 2009 up to May 2010, shown in Table 3. [Table 3 near here] From the table, we see that on their first sitting of the CSA, only one student out of 36 achieved a mark of over $90 \%$; however, by the end of the academic year, this had increased to 7 . The threshold for these students was set at $70 \%$, and while ten students achieved this at the first sitting, this had increased to 18 by the final sitting. More importantly, 25 failed to achieve a mark of $70 \%$ in their first attempt, but this reduced to 11 students eventually.

The improvements were more pronounced with the third year Ordinary Degree class in Mechanical Engineering. These students were required to achieve a mark of $90 \%$ to receive any credit. Their final grades are shown in Table 4, where we can see that 30 out of 34 students achieved $90 \%$ or higher by the end of the year. This includes 11 students who were not in on the day of the diagnostic test, so they only sat the CSA. [Table 4 near here] Those students who failed only made a maximum of two attempts (out of a possible six), and so can be considered to have not engaged with the project in any real way. Of the four students who failed the CSA only one of them passed the end of year Mathematics module. These students were not engaged with any of the module in a consistent manner throughout the year so it is not surprising that they failed the CSA. 


\subsection{Sample Group of Final Year Students}

To ascertain whether their poor core mathematical skills have persisted throughout the course of their degree, it was decided to test a small subgroup of final-year Honours degree students, some of whom had entered directly into the programme, others of whom completed an Ordinary degree first before continuing into the programme. 48 students volunteered to retake the Mathematics Diagnostic Test. No credit was awarded irrespective of how well or badly they did. Their results are shown in Table 5. [Table 5 near here]

As can be seen in the table, 7 students obtained a mark of less than $70 \%$ (the threshold for passing in first year) - all of these students came from an Ordinary degree background. Three of these actually failed to score $50 \%$. This seems to demonstrate that students who have continued through the Engineering course doing more advance mathematics haven't improved their core mathematical skills. Unless a targeted intervention such as the CSA is introduced many of these students will never improve their core mathematical skills. Given that these students volunteered to do the test, there may be significantly more students in final year who still lack many core mathematical skills. These results emphasise that action needs to be taken early in the education of student engineers to address this problem.

\section{Conclusion and Future Work}

\subsection{Conclusion}

By participating in the CSA, there has been a systematic improvement in the core mathematical skills of the students. This is evident both from the results of the students and feedback from the focus groups. The results of the small group of final year students who re-took the Mathematics Diagnostic Test have shown that there may be a 
significant number of students who struggle with basic mathematical concepts throughout their entire degree. Such problems are clearly endemic and will persist if not tackled in a consistent manner. The CSA is one such way to encourage students to address these deficiencies and it is extremely important that this work be rolled out across all first year courses in engineering. This paper provides evidence that we have systematically improved the core mathematics of the vast majority of our students who have participated in this programme. Many of these students have acquired these skills for the first time. At this point there is no evidence that they don't continue to make some of these errors in their other subjects in later years, but what we can say definitively is that prior to this exercise they didn't have these skills at all. It is an iterative process from basic skill development to use of that skill in high pressure situations outside the mathematics class (e.g. in a thermodynamics exam in a later year) and this exercise is an important first step. A full analysis of students' diagnostic scores and examination scripts from later years is beyond the scope of this project but is something we would like to look at in the future. Furthermore we have recently established links with an Institute in Hungary and an Institute in Portugal. We are currently looking at analyzing the performance of students in three different countries on a small subset of our questions.

\subsection{Future Work}

The CSA will now be introduced to all first year Ordinary degree engineering classes. The feedback from the focus groups will be used to improve the process in the coming year, and an anonymous online survey will be provided to students once they have passed the CSA (or on their final attempt). A more advanced version of the test is currently being developed for students in the later years of the programme (Carr et al 2012), as was requested in the focus groups. We will also be looking at retention of 
these basic skills by re-testing groups of students who have passed the CSA in previous years, to ascertain whether these skills have now been properly acquired by these students.

\section{References}

Breen, S., Cleary, J. and O'Shea, A. 2008. An investigation of the mathematical literacy of first year third-level students in the Republic of Ireland. International Journal of Mathematical Education in Science and Technology, 24, pp. 223-229.

Brown, G., Bull, J. and Pendelbury, M. 1997. Assessing student learning in higher education. London: Routledge.

Carr, M., Bowe, B. and Ní Fhloinn, E. 2010. Improving core mathematical skills in engineering undergraduates. In $15^{\text {th }}$ SEFI MWG Seminar on Mathematics in Engineering Education, Wismar, Germany [Online]. Available from: http://sefi.htwaalen.de/Seminars/Wismar2010/SEFI/papers_pdfs/MWG2010_Ca rr_C.pdf [Accessed 5 July 2012]

Carr, M., Murphy E., Bowe, B., and Ní Fhloinn, E. 2012. Addressing continuing mathematical deficiencies with advanced mathematical diagnostic testing. In $16^{\text {th }}$ SEFI MWG Seminar on Mathematics in Engineering Education, Salamanca, Spain [Online]. Available from: http://sefi.htwaalen.de/Seminars/Salamanca2012/16thSEFIMWGSeminar/ficheros/lecturas/Do cuments_pdf/Session5/SEFIMWG12_MCarr.pdf [Accessed 5 July 2012]

Cleary, J. 2007. Diagnostic testing - An evaluation 1998-2007. In S. Close, D. Corcoran \& T. Dooley (Eds.), Proceedings of Second National Conference on Research in Mathematics Education (MEI2) (pp. 215-227), St. Patrick's College, Dublin.

Edwards, P. 1995. Some mathematical misconceptions on entry to higher education. Teaching Mathematics and its Applications, 14(1), pp. 23-27.

Faulkner, F., Hannigan, A., and Gill, O. 2010. Trends in the mathematical competency of university entrants in Ireland by leaving certificate mathematics grade. Teaching Mathematics and its Applications, 29(2), pp. 76-93.

Gill, O. and O'Donoghue, J. 2007. The mathematical deficiencies of students entering third level: An item by item analysis of student diagnostic tests. In S. Close, D. Corcoran and T. Dooley (Eds.), Proceedings of Second National Conference on 
Research in Mathematics Education (MEI2), St. Patrick's College, Dublin, pp. $228-239$.

Marjoram, M., Moore, D., O’Sullivan, C. and Robinson, P. 2008. Implementing a key skills in mathematics initiative. Proceedings of Mathematical Education of Engineers, Loughborough.

Ní Fhloinn, E. 2006. Maths Diagnostic Report, Internal report, Dublin Institute of Technology.

Lawson, D.A. 1997. What can we expect of A level mathematics students? Teaching Mathematics and its Applications, 16(4), pp. 151-156.

Lawson, D.A. 2003. Changes in student entry competencies 1991-2001. Teaching Mathematics and its Applications, 22(4), pp. 171-175.

Lee, S., Harrison, M.C., Pell, G., and Robinson C.L. 2008. Predicting performance of first year engineering students and the importance of assessment tools therein. Journal of the Higher Education Academy Engineering Subject Centre, 3(1), pp. $44-51$.

Lee, S. and Robinson C.L. 2005. Diagnostic testing in mathematics: paired questions. Teaching Mathematics and its Applications, 24(4), pp. 154 - 166.

O’Grady, M. \& Guilfoyle, B. Evidence of Grade Inflation 1994 - 2004 in the Institute of Technology Sector in Ireland. Available from http://www.stopgradeinflation.ie [Accessed October 2012]

Ramsden, P. 1992. Learning to teach in higher education. New York: Routledge.

Robinson, C.L. and Croft, A.C. 2003. Engineering students - diagnostic testing and follow-up. Teaching Mathematics and its Applications, 22(4), pp. 177-181.

Todd, K.L. 2001. An historical study of the correlation between GCE Advanced level grades and the subsequent academic performance of well qualified students in a university engineering department. Mathematics Today, 37(5).

Warwick, J. 2010. Exploring student expectations in mathematics learning and support. Teaching Mathematics and its Applications, 29(1), pp. 14-24. 


\section{Appendix A : Diagnostic Exercise}

\section{Question 1:}

Is $\frac{1}{2}+\frac{2}{3}-\frac{4}{7}=$
a) $\frac{25}{42}$
b) $\frac{-1}{12}$
c) $\frac{12}{21}$
d) $\frac{11}{42}$

\section{Question 2:}

Simon bought 6 concert tickets for himself and his friends. Later, 4 other friends bought additional tickets at the door costing $€ 5$ more per ticket than the original price. The total cost for all of them was $€ 180$. How much did Simon pay for each ticket? Was it:
a) €16
b) €21
c) $€ 23$
d) $€ 18$

\section{Question 3:}

In a quality check of a batch of components, $1.5 \%$ are rejected. If a total of 39 components are rejected, the number in each batch is
a) 2500
b) 2600
c) 3000
d) 2800

\section{Question 4:}

An alloy contains copper, zinc and nickel in the ratio $2: 3: 5$. The mass of zinc in $20 \mathrm{~kg}$ of alloy is:
a) $5 \mathrm{~kg}$
b) $6 \mathrm{~kg}$
c) $7 \mathrm{~kg}$
d) $8 \mathrm{~kg}$

\section{Question 5:}

$$
\sqrt{\frac{3 \times 10^{4} \times 1.2 \times 10^{-1}}{4 \times 10^{-4}}}=
$$
a) $3 \times 10^{-3}$
b) $0.9 \times 10^{-3}$
c) $3 \times 10^{3}$
d) $3 \times 10^{2}$

\section{Question 6:}

The mean of ten items of data is 50 . If 52,47 and 51 are added to the data, then the mean of the thirteen items of data is: 

a) 49
b) 50
c) 51
d) 52

\section{Question 7:}

Which of the following four statements is correct?
a) $\frac{1}{2 x}+\frac{2}{3 x}=\frac{3}{5 x}$
b) $\frac{1}{2 x}+\frac{2}{3 x}=\frac{3}{6 x}$
c) $\frac{1}{2 x}+\frac{2}{3 x}=\frac{5}{6 x}$
d) $\frac{1}{2 x}+\frac{2}{3 x}=\frac{7}{6 x}$

\section{Question 8:}

Simplify $\frac{a^{3} b \times\left(3 a^{2} b^{3}\right)^{2}}{\left(9 a^{2} b^{4}\right)^{1 / 2}}$. Is it
a) $27 a^{8} b^{9}$
b) $3 a^{6} b^{5}$
c) $a^{5} b^{3}$
d) $3 a^{4} b^{5}$

\section{Question 9:}

If $x^{2}-x-6=0$, then the values of $x$ are
a) 6 and 1
b) 3 and -2
c) -3 and 2
d) -6 and 1

\section{Question 10:}

If $\frac{1}{2}(3 x-7)-\frac{1}{3}(7-5 x)=10$, the value of $x$ is
a) 3
b) 4
c) 5
d) 6

\section{Question 11:}

If $\tan \theta=0.75$, then $\sin \theta$ is equal to
a) $\frac{4}{3}$
b) 0.8
c) $\frac{3}{5}$
d) $\frac{5}{3}$

\section{Question 12:}

The equation of a straight line is $8 x+4 y-6=0$. The slope (gradient) of the line is
a) 8
b) 4
c) -2
d) 2

\section{Question 13:}

If $5 x+2 y=14$ and $3 x-4 y=24$,
a) $x=4$ and $y=3$
b) $x=3$ and $y=4$
c) $x=4$ and $y=-3$
d) $x=-4$ and $y=3$

\section{Question 14:}


If $E=\frac{1}{2} m v^{2}+m g h$, then $v=$
a) $\sqrt{\frac{2(E-m g h)}{m}}$
b) $\sqrt{\frac{m}{2(E-m g h)}}$
c) $\sqrt{\frac{E m g h}{2}}$
d) $\frac{2 E^{2}}{\sqrt{m g h}}$

\section{Question 15:}

$2.5 \mathrm{~m}^{3}$ is equal to
a) $2,500,000 \mathrm{~cm}^{3}$
b) $250 \mathrm{~cm}^{3}$
c) $2,500 \mathrm{~cm}^{3}$
d) $25,000 \mathrm{~cm}^{3}$

\section{Question 16:}

If $y=\operatorname{Cos}^{2}\left(x^{2}-3 x\right)$, at $x=3^{\circ}$, the value of $y$ is
a) 1
b) 0
c) -1
d) $\sqrt{3}$

\section{Question 17:}

Is $\frac{36 x^{4} y^{3} \times 25 x^{2} y^{3}}{6 x y^{-1} \times 5 x^{3} y^{6}}$ equal to
a) $30 x^{2} y$
b) $\frac{6 x^{2}}{y}$
c) $25 x y^{-1}$
d) $30 x y^{2}$

\section{Question 18:}

Given $x=A+(B-A)\left[\frac{C}{C-D}\right]$

then the value of $x$ when $A=0.5, B=0.6, C=1000$ and $D=2000$ is
a) 0.2
b) 1200.6
c) 0.5333
d) 0.4

\section{Question 19:}

$\log _{2} 16=$
a) 4
b) 8
c) 14
d) 18

\section{Question 20:}

If $y=x^{3}+k x^{2}+4 x+7$ and the value of $\frac{d y}{d x}=4$ when $x=-2$, then $k=$
a) 0
b) 1
c) 2
d) 3 


\section{Solutions:}

$\begin{array}{llll}1(\mathrm{a}) & 6(\mathrm{~b}) & 11(\mathrm{c}) & 16(\mathrm{a}) \\ 2(\mathrm{a}) & 7(\mathrm{~d}) & 12(\mathrm{c}) & 17(\mathrm{a}) \\ 3(\mathrm{~b}) & 8(\mathrm{~b}) & 13(\mathrm{c}) & 18(\mathrm{~d}) \\ 4(\mathrm{~b}) & 9(\mathrm{~b}) & 14(\mathrm{a}) & 19(\mathrm{a}) \\ 5(\mathrm{c}) & 10(\mathrm{c}) & 15(\mathrm{a}) & 20(\mathrm{~d})\end{array}$




\section{Appendix B}

Students are initially given the Diagnostic test. This test lasts for 90 minutes, to allow for acclimatisation to the online test regime. It also gives the instructors extra time in case there are any problems with registrations, first year students can't find the room, can't $\log$ on etc. After the initial test students are given access to a website with targeted resources. Subsequent tests last for 60 minutes. We find that this is more than ample time for subsequent tests, now that the students are familiar with the process. The 60 minute time slot is important as most of the testing is done at lunchtime, and it is very difficult to consistently find 90 minutes slots of availability. After the second test special classes are provided every 2 weeks on problem topics. These classes are voluntary but on average 10-20 students attend these classes. The students have the opportunity to sit the test on average every two weeks. Students are allowed to sit the test as many times as they require, but no-one has yet sat the test 6 times without passing. In general students who fail are those who haven't engaged with the process.

\section{Pass Mark}

\begin{tabular}{|l|l|l|}
\hline Year & Pass Mark & No. of questions correct \\
\hline First year & $70 \%$ & $14 / 20$ \\
\hline Second year & $80 \%$ & $16 / 20$ \\
\hline Third year & $90 \%$ & $18 / 20$ \\
\hline
\end{tabular}




\begin{tabular}{|l|c|c|c|}
\hline Course & Year & Leaving Certificate Points & No. of students \\
\hline Preliminary Engineering & 1 & 290 & $\mathbf{3 6}$ \\
\hline Building Services Engineering & 1 & 150 & $\mathbf{2 9}$ \\
\hline Mechanical Engineering & 1 & 315 & $\mathbf{7 2}$ \\
\hline Manutronics Automation & 2 & 150 & $\mathbf{1 0}$ \\
\hline Mechanical Engineering & 3 & 305 & $\mathbf{3 4}$ \\
\hline
\end{tabular}

Table 1. List of courses included in the project.

\begin{tabular}{|l|c|c|c|c|c|}
\hline Course & Year & Mean Mark & \# Students > 70\% & \#Students > 90\% & No. of students \\
\hline Honours Engineering & $\mathbf{1}$ & $\mathbf{8 0 \%}$ & $\mathbf{7 9 \%}$ & $\mathbf{2 0 \%}$ & $\mathbf{8 7}$ \\
\hline Preliminary Engineering & 1 & $48 \%$ & $\mathbf{2 2 \%}$ & $\mathbf{0 \%}$ & $\mathbf{3 6}$ \\
\hline Building Services & 1 & $65 \%$ & $\mathbf{4 8 \%}$ & $\mathbf{1 4 \%}$ & $\mathbf{7 2}$ \\
Engineering & & & & & $\mathbf{1 5 \%}$ \\
\hline Mechanical Engineering & 1 & $61 \%$ & $\mathbf{4 2 \%}$ & $\mathbf{0 \%}$ & $\mathbf{1 0}$ \\
\hline Manutronics Automation & 2 & $45 \%$ & $\mathbf{2 0 \%}$ & $\mathbf{3 0 \%}$ & \\
\hline Mechanical Engineering & 3 & $75 \%$ & $\mathbf{7 0 \%}$ & & $\mathbf{3 4}$ \\
\hline
\end{tabular}

Table 2. List of courses tested and marks received in the diagnostic test 


\begin{tabular}{|l|c|c|c|c|}
\hline Preliminary Engineering & Mean Mark & $\begin{array}{c}\text { \# Students } \\
<\mathbf{7 0 \%}\end{array}$ & $\begin{array}{c}\text { \# Students } \\
>\mathbf{7 0 \%}\end{array}$ & $\begin{array}{c}\text { \# Students } \\
\mathbf{9 0 \%}\end{array}$ \\
\hline First Attempt & $\mathbf{5 4 \%}$ & $\mathbf{6 9 \%}$ & $\mathbf{2 8 \%}$ & $\mathbf{3 \%}$ \\
\hline December 2009 & $\mathbf{6 5 \%}$ & $\mathbf{4 4 \%}$ & $\mathbf{3 9 \%}$ & $\mathbf{1 7 \%}$ \\
\hline May 2010 & $\mathbf{7 3 \%}$ & $\mathbf{3 1 \%}$ & $\mathbf{5 0 \%}$ & $\mathbf{1 9 \%}$ \\
\hline
\end{tabular}

Table 3. Grades of Preliminary Engineering students $(\mathrm{N}=36)$ in the Core Skills Assessment (CSA).

\begin{tabular}{|c|c|c|c|c|}
\hline $\mathbf{3}^{\text {rd }}$ Mechanical & Mean Mark & $\begin{array}{c}\text { \# Students } \\
<\mathbf{7 0 \%}\end{array}$ & $\begin{array}{c}\text { \# Students } \\
>\mathbf{7 0 \%}\end{array}$ & $\begin{array}{c}\text { \# Students } \\
\text { Engineering }\end{array}$ \\
\hline First Attempt* & $\mathbf{7 5 \%}$ & $\mathbf{0 \%}$ & $\mathbf{7 0 \%}$ & $\mathbf{3 0 \%}$ \\
\hline May 2010 & $93 \%$ & $\mathbf{3 \%}$ & $\mathbf{9 \%}$ & $\mathbf{8 8 \%}$ \\
\hline
\end{tabular}

Table 4. Final grades of $3^{\text {rd }}$ year Mechanical Engineering students $(\mathrm{N}=34)$ in the Core Skills Assessment (CSA).* 11 students missed the sitting of the diagnostic test and only completed the CSA. 


\begin{tabular}{|l|c|c|c|}
\hline Final Year Engineering & $\begin{array}{c}\text { \# Students } \\
<\mathbf{7 0 \%}\end{array}$ & $\begin{array}{c}\text { \# Students } \\
>\mathbf{7 0 \%}\end{array}$ & $\begin{array}{c}\text { \# Students } \\
\end{array}$ \\
\hline Students who entered directly into Honours & $\mathbf{0}$ & $\mathbf{4 4 \%}$ & $\mathbf{5 6 \%}$ \\
degree $(\mathrm{N}=25)$ & & & \\
\hline Students who entered Honours degree via & $\mathbf{3 0 \%}$ & $\mathbf{2 6 \%}$ & $\mathbf{4 4 \%}$ \\
Ordinary degree route $(\mathrm{N}=23)$ & & & \\
\hline Total & $\mathbf{1 5 \%}$ & $\mathbf{4 5 \%}$ & $\mathbf{4 0 \%}$ \\
\hline
\end{tabular}

Table 5. Results of final year students $(\mathrm{N}=48)$ who volunteered to retake the Mathematics Diagnostic Test. 